\title{
Helmet Use among Two Wheeler Female Riders
}

\author{
Rizwan Khan ${ }^{1}$ Nadia Krishnan ${ }^{1}$ Manju Dhandapani ${ }^{1} \quad$ Sivashanmugam Dhandapani² \\ ${ }^{1}$ National Institute of Nursing Education, Post Graduate Institute of \\ Medical Education and Research (PGIMER), Chandigarh, India \\ 2Department of Neurosurgery, PGIMER, Chandigarh, India \\ Address for correspondence Manju Dhandapani, PhD, National \\ Institute of Nursing Education, PGIMER, Chandigarh, India \\ (e-mail: manjuseban@gmail.com).
}

Indian J Neurosurg 2019;8:34-38

\begin{abstract}
Keywords

- traumatic brain injury

- helmet

- pillion rider

Introduction The frequency of traffic collisions in India is among the highest in the world with more than 135,000 traffic collision-related deaths occurring every year. The "Global Status Report on Road Safety" listed by the World Health Organization identified the major causes of injury as driving over the speed limit, driving under the influence, and not using helmets and seat belts. Women face unique challenges after traumatic brain injury, due to differential laws and their enforcement.

Objectives To assess the use of helmet among female hospital workers (nurses, hospital attendants, sanitary attendants, and security guards) and their attitude toward helmet wearing.

Methods Purposive sampling was done among female two-wheeler-riding hospital workers. A questionnaire was developed to study the use of helmet and an attitude Likert scale for assessing attitude toward wearing helmet. Data were collected, coded, and analyzed using SPSS software version 21.

Results Of the total 89 women enrolled, $46.4 \%$ were mostly pillion riders, and $33 \%$ were mostly drivers. Only $19 \%$ were using helmet consistently, despite $93 \%$ owning it. Eighty-eight percent of the regular users were younger than 25 years, while $80 \%$ of the non-users were above 25 years. Even among regular drivers, 40\% never wore helmet. Eighty-two percent of the non-users were merely casual despite knowing about its advantages.

Conclusion Helmet use is very poor among women (both drivers and pillion riders), despite working in hospital environment and owning helmet. Stricter enforcement of helmet law is needed, as education and knowledge per-se may not instil helmet use.
\end{abstract}

\section{Introduction and Need of the Study}

Each year road traffic accidents (RTAs) claim some 600,000 lives, and 30 times this number, that is over 15 million, are injured according to the World Health Organization (WHO). This represents more than one life lost every minute and an injury every two seconds. Two third of these victims are from the third world countries. ${ }^{1}$ The frequency of traffic collisions in India is among the highest in the world. A National Crime Records Bureau (NCRB) report revealed that every year, more than 135,000 traffic collision-related deaths occur in India. ${ }^{2}$ The "Global Status Report on Road Safety" published by the WHO identified the major causes of traffic collisions as driving over received

June 24, 2018

accepted

July 20, 2018

published online

April 22, 2019 the speed limit, driving under the influence of alcohol, and not using helmets and seat belts. ${ }^{2}$

A study on injury pattern among RTA cases from south India shows head injuries were common among motorized two wheelers (22.6\%), and none used helmet. ${ }^{3}$ A prevalence study on helmet use among motorcycle riders in Vietnam showed that the overall weighted average of helmet use for motorcyclists was $29.94 \%$, with male drivers more likely to wear helmets than female drivers. ${ }^{4}$ Present study was undertaken with the objectives to assess the use of helmet among the selected female two-wheeler-riding hospital workers (nurses, hospital attendants, sanitary attendants, and security guard) and to study the attitude of selected hospital workers toward helmet wearing.
License terms Society of India
DOI https://doi.org/

$10.1055 / \mathrm{s}-0039-1686963$

ISSN 2277-954X. 


\section{Material and Methods}

Quantitative non-experimental research design was adopted to conduct a study in Post Graduate Institute of Medical Education and Research (PGIMER), Chandigarh. Using purposive sampling technique, 90 hospital female workers who ride two wheelers were enrolled. Permission was taken from the Head of Neurosurgery Department, and ethical clearance was obtained from the ethical committee, PGIMER, Chandigarh. A self-prepared questionnaire was developed to collect the data from two-wheeler female riders, where a proportion of subjects as driver and pillion riders was assessed for use of helmet, opinion on need of wearing helmet, and reason for not wearing helmet. It also included the quality of helmet, procurement of helmet, and owner of helmet. Three-point Likert scale was also used for assessing their attitude toward wearing helmet. Analysis of data was done in accordance with the objectives laid down for the study using descriptive and inferential statistics in SPSS software version 21 (SPSS Inc.).

\section{Results}

Maximum 36\% participants were in the age group (in years) of 21 to 25 , followed by $25 \%$ in 36 to $40,17 \%$ in 15 to $20,13 \%$ in 26 to 30, and least in 31 to 35, that is, 9\%. Among the subjects, $71.9 \%$ were Hindu, and $25 \%$ were Sikh. A total of $20.2 \%$ were staff nurses, and the rest $25.8 \%$ were from other categories (- Table $\mathbf{1}$ ).

-Fig. 1 shows that 33\% (18.4 + 14.5\%) subjects were mostly drivers, and $42 \%$ were driving sometimes.

-Fig. 2 shows that $46.4 \%$ ( $38.4+8 \%$ ) subjects were pillion riders mostly, and $36 \%$ were pillion riders sometimes.

-Fig. 3 shows that $51 \%$ of female hospital staff never used helmet, and only $19 \%$ were using helmet every time. This is despite the fact that $93 \%$ of subjects owned a helmet. Eighteight percent of the regular users were younger than 25 years, while $80 \%$ of the non-users were above 25 years. Even among regular drivers, $40 \%$ never wore helmet.
Table 1 Demographic profile of subjects

\begin{tabular}{|c|c|}
\hline Variables & Frequency (\%) \\
\hline \multicolumn{2}{|l|}{ Age (years) } \\
\hline $15-20$ & $15(17)$ \\
\hline $21-25$ & $32(36)$ \\
\hline $26-30$ & $12(13)$ \\
\hline $31-35$ & $8(9)$ \\
\hline $36-40$ & $22(25)$ \\
\hline \multicolumn{2}{|l|}{ Religion } \\
\hline Hindu & $64(7,109)$ \\
\hline Sikh & $22(25)$ \\
\hline Christian & $2(2)$ \\
\hline Others & $1(1)$ \\
\hline \multicolumn{2}{|l|}{ Designation } \\
\hline Students & 48 (53.9) \\
\hline Staff nurse & $18(20.2)$ \\
\hline Others & $23(25.8)$ \\
\hline
\end{tabular}

-Fig. 4 shows that $82 \%$ subjects wore helmet as it prevents head injury and only $6 \%$ due to the fear of challan/police.

-Fig. 5 shows that out of 72 subjects who never or sometimes wear helmet, $53 \%$ gave ignorance as their reason for not using helmet, $16 \%$ found it uncomfortable, $10 \%$ were not using it because of lack of strict rule, and the rest were not using because of irritation, poor visibility, and use of spectacle. Eighty-two percent of the non-users were merely casual despite knowing about its advantages.

-Fig. 6 shows that $89 \%$ subjects agree that helmet decreases injury chance, $87 \%$ say that it is necessary to wear helmet, $86 \%$ believes that it is their responsibility to wear helmet, and $85 \%$ say helmet should be used by experienced as well as pillion drivers.

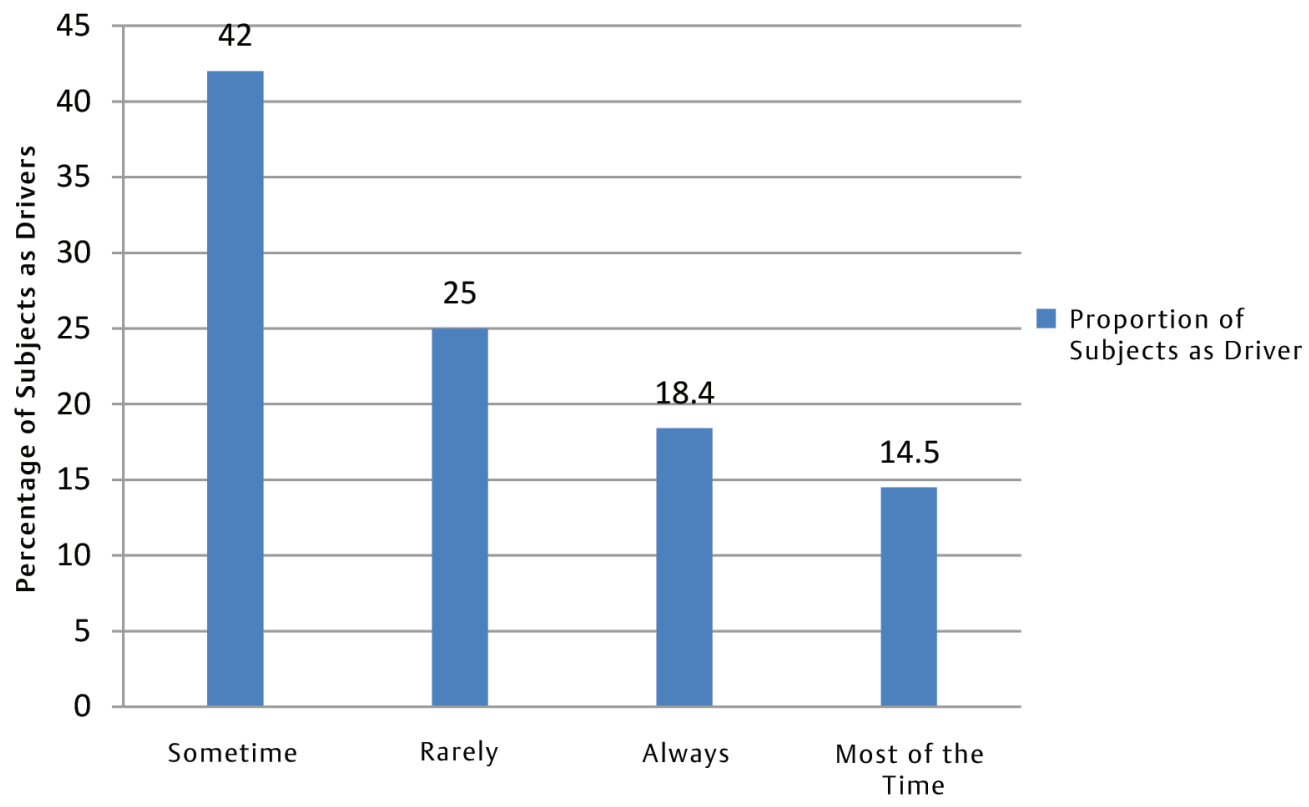

Fig. 1 Proportion of subjects as driver. 


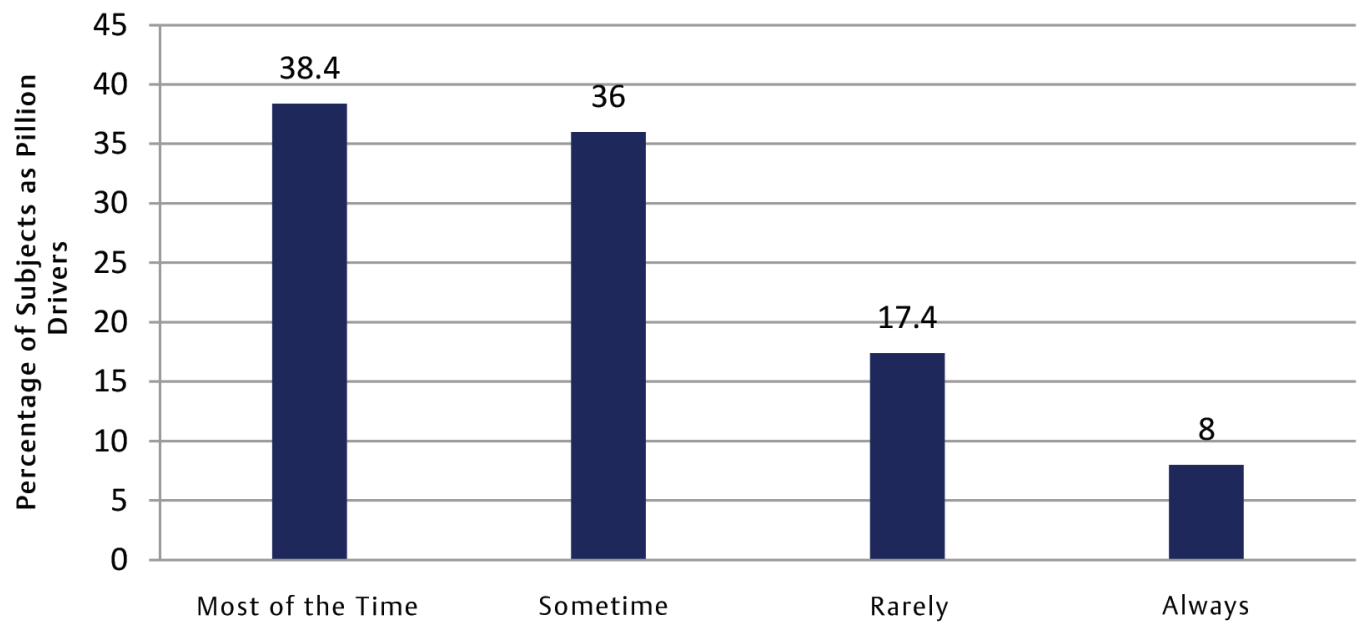

Fig. 2 Proportion of pillion drivers.
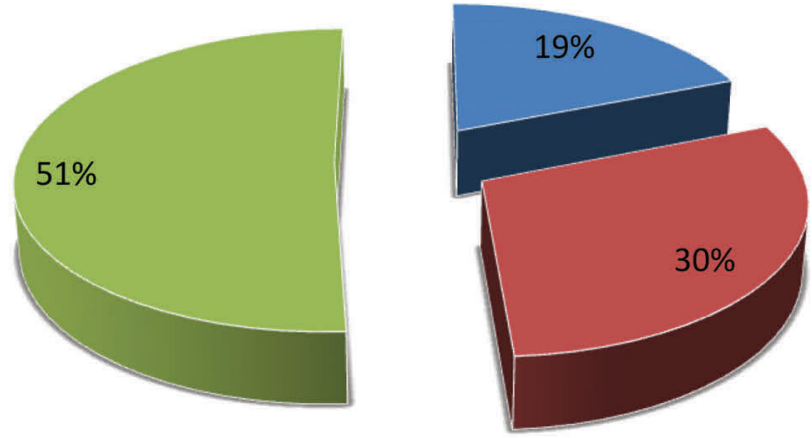

- Always

- Sometimes

Never

Fig. 3 Use of helmet by female hospital staff.

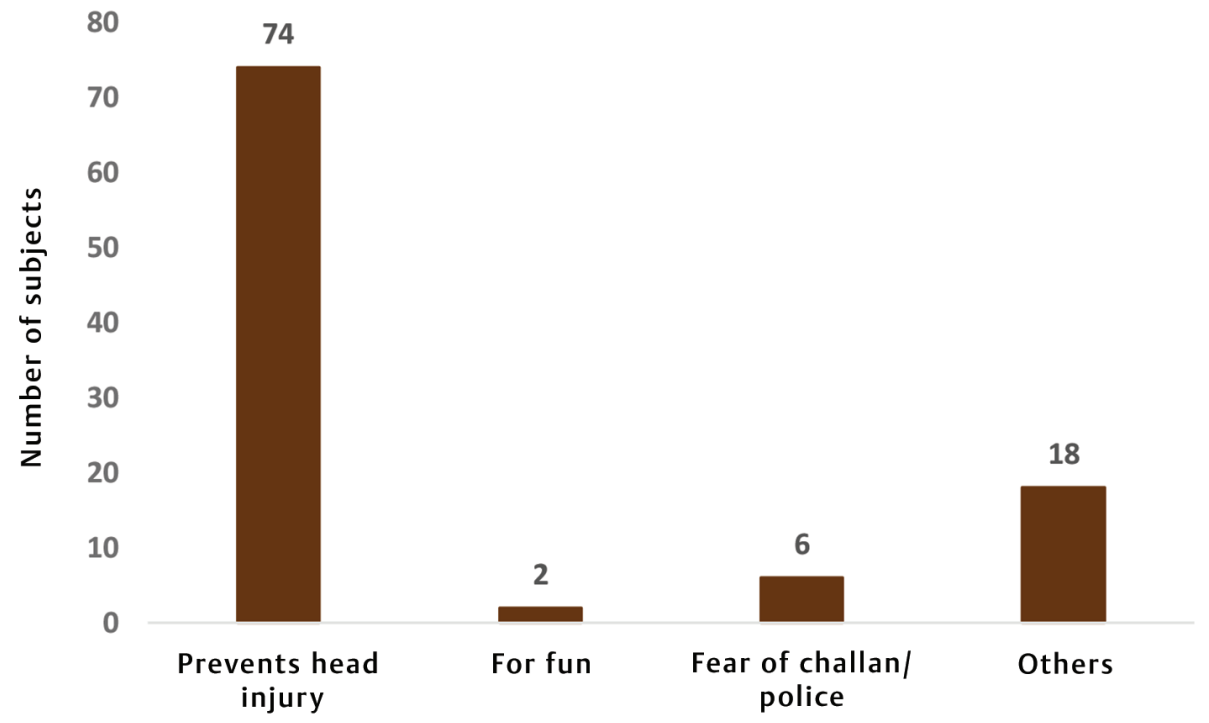

Fig. 4 Opinion of subjects regarding need of wearing helmet.

\section{Discussion}

Head injury is a major cause of disability and death among the productive years of life. ${ }^{5-7}$ The WHO recognized that the major causes of traffic collisions are driving over the speed limit, driving under the influence, and not using helmets and seat belts. Helmets are known to protect from 


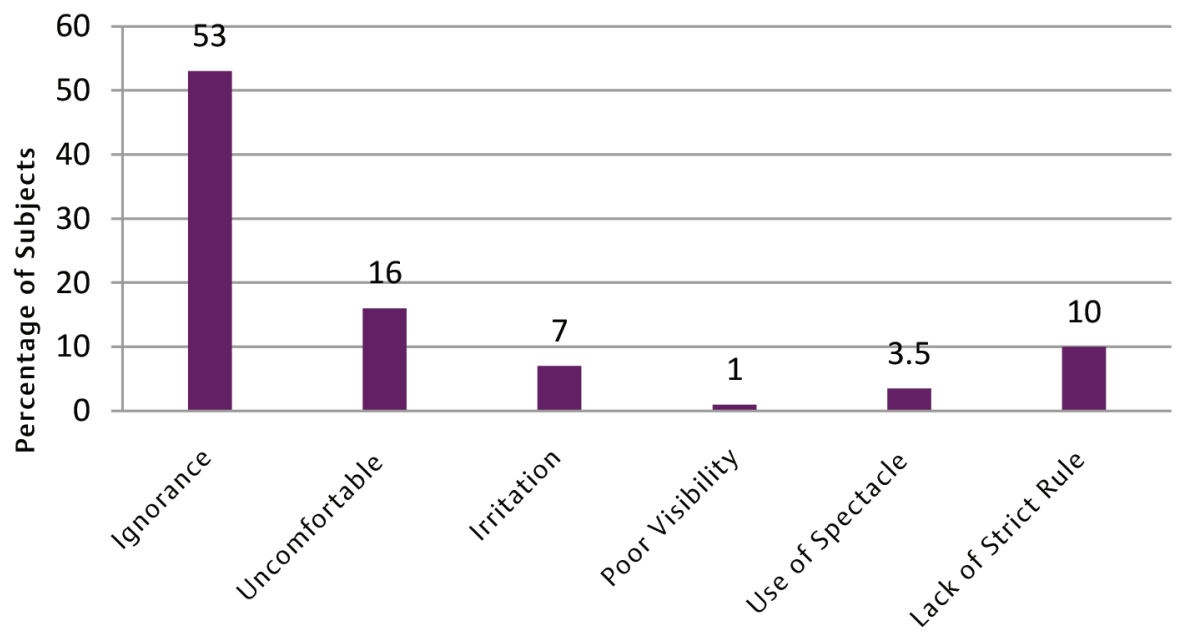

Fig. 5 Reasons of not wearing helmet by the drivers.
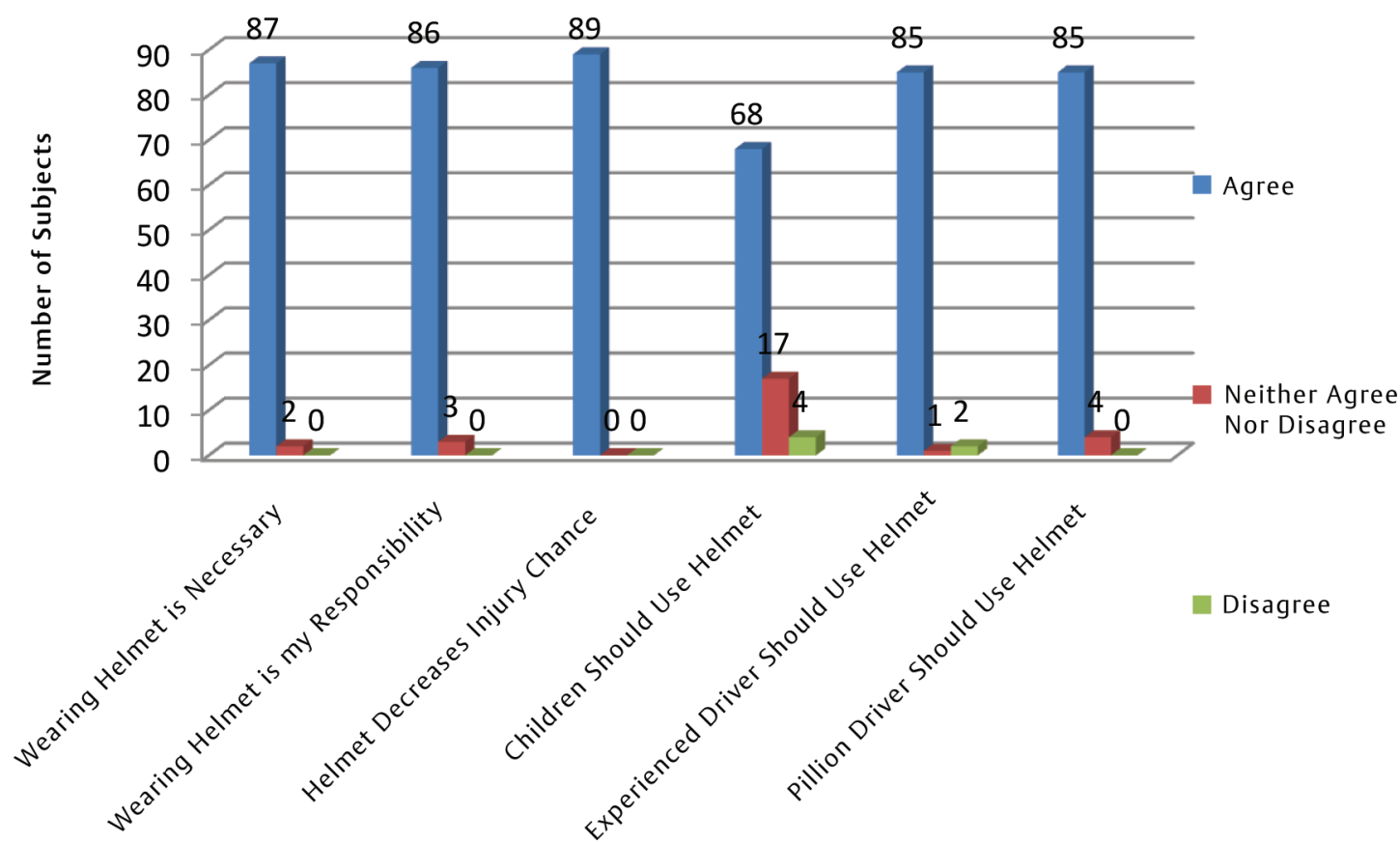

Fig. 6 Attitude of subjects toward wearing helmet.

traumatic brain injury (TBI) in case of roadside accidents. Because of which present study was conducted where only $19 \%$ of the subjects were using helmet while riding two-wheeler which was similar to the study of Kalantharakath and Iyer ${ }^{8}$ with $30 \%$ use and $16.2 \%$ in Fong et $\mathrm{al}^{9}$ and was contradictory to the study of Bao et al where $64 \%$ respondents were using helmet while riding. ${ }^{10}$ Overwhelming majority of the subjects were having helmet but were not using it. Although majority of the subjects knew that helmet protects from TBI and had a positive attitude toward it, the actual practice of wearing one was very low. Ignorance, irritation, discomfort, and lack of strict rules were some of the quoted reasons for not wearing helmet.
Maximum 36\% participants were in the age group of 21 to 25 and least in 31 to 35 years, i.e., 9\%. More than half of the subjects (54\%) were from nursing department. Only $18.4 \%$ subjects were driving always, and $38.4 \%$ subjects were pillion rider for most of the time. Fifty-one percent of female hospital staff never used helmet during driving, and only $19 \%$ were using helmet every time. Eighty-two percent subjects wear helmet as it prevents head injury, similar to the study results of Kalantharakath et $\mathrm{al}^{8}$ and only $6 \%$ for the fear of challan/police, which was contradictory to the study results of Bao et al (40\%). ${ }^{10}$ Out of 72 subjects who never or sometimes wear helmet, only $10 \%$ were not using it because of lack of strict rule, and the rest were not using 
because of irritation, poor visibility, and use of spectacle, whereas other reasons for not using helmets were different, such as the way they look with helmet. ${ }^{9}$ Eighty-nine percent subjects agree that helmet decreases injury chance, $87 \%$ say that it is necessary to wear helmet, $86 \%$ believe that it is their responsibility to wear helmet, and $85 \%$ say helmet should be used by experienced as well as pillion drivers.

The importance of helmet use is not merely because of protection from primary impact injury, but also from the cascading effect of secondary micro-ischemic sequalae. ${ }^{11,12}$

\section{Conclusion}

Helmet use is very poor among women (both drivers and pillion riders) despite working in hospital environment and owning helmet. Stricter enforcement of helmet law is needed, as education and knowledge may not instil helmet use.

\section{Conflicts of Interest}

None.

\section{Acknowledgments}

The authors would like to express their great appreciation to the National Institute of Nursing Education for the permissions to conduct this research and sincerely thank all the participants for their co-operation and support for the smooth conduct of the study. The authors are also grateful to authors of all those articles, journals, and books from where the literature for this article has been reviewed and discussed.

\section{References}

1 Downing $A$, et al. International overview of road safety. International Workshop on Prevention and Control of Traffic Accidents and Injuries (24 November-3 December, 1992), New Delhi, India: 4-12
2 Krishnan M. India has the highest number of road accidents in the world. Deutsche Welle. April 29, 2010:1

3 Jha N, Srinivasa DK, Roy G, Jagdish S. Injury pattern among road traffic accident cases: A study from South India. Ind J Comm Med 2003;28(2):85-90

4 Hung DV, Stevenson MR, Ivers RQ. Prevalence of helmet use among motorcycle riders in Vietnam. Inj Prev 2006;12(6):409-413

5 Dhandapani S, Bajaj A, Gendle C, et al. Independent impact of plasma homocysteine levels on neurological outcome following head injury. Neurosurg Rev 2018;41(2):513-517

6 Dhandapani S, Sarda AC, Kapoor A, Salunke P, Mathuriya SN, Mukherjee KK. Validation of a new clinico-radiological grading for compound head injury: implications on the prognosis and the need for surgical intervention. World Neurosurg 2015;84(5):1244-1250

7 Dhandapani SS, Manju D, Vivekanandhan S, Agarwal M, Mahapatra AK. Prospective longitudinal study of biochemical changes in critically ill patients with severe traumatic brain injury: factors associated and outcome at 6 months. Indian J Neurotrauma. 2010;7(01):23-27

8 Kalantharakath T, Iyer R. Helmet attitudes and practices among university students of dental and medical professional courses in Vadodara, India. J Interdiscipl Med Dent Sci 2015;3:180

9 Fong MC, Measelle JR, Dwyer JL, et al. Rates of motorcycle helmet use and reasons for non-use among adults and children in Luang Prabang, Lao People's Democratic Republic. BMC Public Health 2015;15:970

10 Bao J, Bachani AM, Viet CP, Quang N, Nguyen N, Hyder AA. Trends in motorcycle helmet use in Vietnam: results from a four-year study. Public Health 2017;144S:S39-S44

11 Dhandapani S, Aggarwal A, Srinivasan A, et al. Serum lipid profile spectrum and delayed cerebral ischemia following subarachnoid hemorrhage: Is there a relation? Surg Neurol Int 2015;6(Suppl 21):S543-S548

12 Mukherjee KK, Dhandapani S, Sarda AC, et al. Prospective comparison of simple suturing and elevation debridement in compound depressed fractures with no significant mass effect. Acta Neurochir (Wien) 2015;157(2):305-309 